\title{
Christian Thomasius e a Reformulação Universitária na Aufklärung*
}

\author{
Christian Thomasius and the Redesign of the Universities in the \\ Aufklärung
}

\author{
Diego Kosbiau Trevisan \\ diegokosbiau@hotmail.com \\ (Universidade Federal de Santa Catarina, Santa Catarina, Brasil)
}

\begin{abstract}
Resumo: 0 artigo tem por objetivo explorar o significado de Christian Thomasius (1655-1728) para o primeiro período do Esclarecimento alemão (Aufklärung), apontando sobretudo a relevância institucional da atuação de Thomasius na reformulação dos currículos universitários com a introdução ou reformulação de disciplinas como a Policey e as Kameralwissenschaften. Essas disciplinas tinham um propósito eminentemente prático de formar um grupo de funcionários públicos comprometidos com a administração eficiente do governo, de acordo com a especificidade do Esclarecimento alemão no cenário mais amplo do lluminismo europeu.
\end{abstract}

Palavras-chave: Thomasius; iluminismo; política; universidade; esclarecimento.

\begin{abstract}
This paper aims to explore the meaning of Christian Thomasius (16551728) for the first period of the German Enlightenment (Aufklärung) by focusing specially on his institutional role for the redesign of university curricula with the introduction or reformulation of subjects such as the Policey and the Kameralwissenschaften. These disciplines had an eminently practical purpose of forming a group of civil servants committed to the efficient administration of the government, what corresponds to the specificity of German Enlightenment in the broader European Enlightenment scenario.
\end{abstract}

Keywords: Thomasius; enlightenment; politics; university; German Enlightenment.

DOI: http://dx.doi.org/10.11606/issn.2318-9800.v25i4p255-270

O Iluminismo na Alemanha - o qual chamaremos aqui de Aufklärung ou Esclarecimento - tem certas particularidades em relação aos demais movimentos das Luzes que surgiram no continente europeu e, de modo mais amplo, no mundo nos séculos 17 e 18 (Trevisan, 2020). Podemos identificar inicialmente dois traços centrais que caracterizam essa especificidade da Aufklärung: primeiro, seu forte caráter anticlerical, que, no entanto, não pode ser confundido com um puro e simples combate radical à religião enquanto tal, como, por exemplo, é o caso de parte do movimento das Luzes na França; segundo, a sua marcada impregnação áulica, uma vez que os principais porta-vozes da Aufklärung eram todos egressos das fileiras dos funcionários públicos estatais (Staatsbeamte): professores universitários,

\footnotetext{
* Esse trabalho contou com apoio da Fundação de Amparo à Pesquisa do Estado de São Paulo (FAPESP).
} 
conselheiros dos príncipes (Fürsten), bibliotecários, etc. Esses dois traços, por sua vez, nos levam a uma outra marca distintiva da Aufklärung: em comparação, por exemplo, com as Lumières e com o Enlightenment, "na Alemanha a Aufklärung é bem fortemente utilitarista, orientada à 'utilidade', ela [a Aufklärung] ambiciona ter efeitos prático-econômicos e na educação popular” (Göhler, 2011, p. 17).

Sob esse pano de fundo começamos a entender melhor a relevância de Christian Thomasius para o período inicial do Esclarecimento, a Frühaufklärung. Na sequência, será discutido como Thomasius foi importante para a fundação e consolidação da Universidade de Halle como um centro intelectual desconfessionalizado no ambiente da Aufklärung (I). Nesse contexto, a reformulação do currículo universitário realizada em Halle inverteu a antiga ordem hierárquica das disciplinas, destronando a teologia como a principal delas e, em seu lugar, introduzindo a jurisprudência e as Kameralwissenschaften, disciplinas eminentemente práticas destinadas a formar funcionários públicos e a fomentar a prosperidade do estado (II). Por fim, uma disciplina das Kameralwissenschaften será analisada em maior detalhe, a saber, a Polizey, entendida como uma doutrina da prudência que, recusando a antiga compreensão aristotélico-luterana da política como doutrina das virtudes dos governantes, estipula uma espécie de "técnica de governo" para estados secularizados (III).

\section{A Universidade de Halle e a secularização dos territórios confessionais}

Thomasius foi um dos artífices da fundação da Universidade de Halle em 1694, um dos centros mais importantes da Aufklärung. Ele encontrou em Halle um ambiente propício para sua tarefa institucional central: a secularização da sociedade e sua guinada à prática. As características políticas e religiosas de Halle, localizada no território de Prússia-Brandemburgo, explicam o protagonismo de sua Universidade para a Frühaufklärung. No território de Brandemburgo,

a dinastia dos Hohenzollern havia se convertido ao calvinismo no início do século 17 - buscando unir a reforma religiosa e a formação de um estado territorial como parte da "segunda reforma" do norte da Alemanha -, enquanto os estados territoriais de Brandemburgo e Prússia permaneciam decididamente luteranos, tratando sua religião como um direito imperial (Hunter, 2007, p. 7).

O esforço dos Hohenzollern de propor um estado territorial bi-confessional que, assim, salvaguardasse uma convivência social tolerante e pacífica, correspondia ao estado-de-coisas que se abriu após a Paz de Westfália:

Ao reconhecer os príncipes territoriais como signatários independentes, os Tratados de Westfália (1648), intermediados pelos franceses, deram reconhecimento legal internacional a um sistema pós-imperial de estados territoriais. Ao mesmo tempo, ao declarar a legitimidade das três principais religiões (luteranismo, catolicismo e calvinismo), independente de qual fosse a religião da casa dominante, os tratados 
assinalaram uma certa secularização ou dessacralização da política, inicialmente obrigando formas limitadas de tolerância religiosa (...). Embora seu desenvolvimento completo ainda residisse no futuro, nós podemos reconhecer aqui a emergência de uma relação recíproca entre uma certa "autonomização" do estado - isto é, a tentativa de tornar o estado territorial independente de comunidades religiosas ou morais que ele precisa governar - e uma certa "liberalização" da esfera privada (religião, família, comércio), agora declarada como repousando fora da preocupação exclusiva do estado territorial com a segurança (Hunter, 2004, p. 578).

As iniciativas dos Hohenzollern de reformar a constituição religiosa de Brandemburgo aplacaram a ortodoxia luterana, possibilitando uma coexistência pacífica com a parcela calvinista da comunidade e propiciando um ambiente mais tolerante do que em outros territórios alemães (Hunter, 2007). A casa Hohenzollern estava então convicta de que tal ambiente de tolerância impulsionaria a incorporação dos demais estados imperiais ao território da Prússia-Brandemburgo, mas para isso era preciso extinguir a ideia de uma religião ou confissão oficial de estado. Para tanto, contudo, os oficiais políticos, jurídicos e religiosos tinham de conceber a sua função pública como independente da religião que professavam enquanto indivíduos privados. Isso envolvia, com efeito, reformar as instituições de ensino do estado territorial, construindo as condições para um ensino não impregnado pela ortodoxia luterana que dominava grande parte das universidades dos territórios alemães. Uma das primeiras universidades a serem "reformadas" nesse sentido foi a de Frankfurt an der Oder, transformada numa universidade bi-confessional: luterana e calvinista. Ainda em Frankfurt an der Oder, onde defendeu seu doutorado e teve seu primeiro conflito com a teologia luterana, Thomasius chegou à convicção de que os teólogos deveriam ser tratados como "pessoas privadas" sem poder para taxar algum teórico como "herege" - esta prerrogativa deveria caber unicamente ao Fürst (Thomasius, 2001, p. 5-6). ${ }^{1}$

Ao longo da década de 1680, após ter terminado seus estudos em Frankfurt an der Oder e retornado a Leipzig, cidade onde nasceu, Thomasius redige uma série de pequenos escritos polêmicos dirigidos contra o aristotelismo protestante escolástico dominante em sua terra natal. Ele defende o direito natural profano de Pufendorf, ataca o direito natural cristão da ortodoxia luterana (sobretudo de Alberti e Carpzov) e participa de uma série de controvérsias políticas e religiosas, sempre tomando o partido do eleitor de Brandemburgo e posicionando-se contra a Saxônia e os luteranos ortodoxos. Em decorrência de seus escritos, em 1689 Thomasius foi impedido pelo Consistório Luterano Superior de ensinar na Universidade de Leipzig. Essa sentença

\footnotetext{
1 Como escreve Hunter, "Frankfurt [an der Oder] propiciou ao jovem Thomasius um meio político e cultural que the permitiu assimilar o direito natural de Pufendorf e desenvolver doutrinas políticas e jurídicas orientadas para o governo desconfessionalizado de um estado multiconfessional. Com isso, consolidou-se sua oposição à cultura política e religiosa de sua universidade natal, em Leipzig" (Hunter, 2007, p. 8).
} 
foi o que desencadeou sua ida a Brandemburgo e à então recém fundada Universidade de Halle, onde a faculdade de jurisprudência receberia inédito protagonismo. A Universidade de Halle fora idealizada para enfraquecer o controle da ortodoxia luterana por meio da preeminência da faculdade secular de direito e pela contratação de pietistas luteranos não ortodoxos para a faculdade de teologia, sob a direção de A. H. Francke (Hammerstein, 1972, p. 9-10). Emergindo sob essas circunstâncias, a nova universidade oferecia a seus acadêmicos uma extraordinária liberdade intelectual em relação à ortodoxia luterana, ainda que no interior de uma instituição sob estrito controle de uma corte monárquica inclinada a usá-la para fornecer ao estado territorial uma elite dominante desconfessionalizada. Na interpretação de I. Hunter, três movimentos intelectuais a princípio conflitantes entre si - a saber, a filosofia jurídica civil, o pietismo e o racionalismo metafísico - encontravam-se, juntos, em Halle, uma instituição de ensino que permitia experimentações intelectuais, mas sem perder a sensibilidade para conflitos religiosos e políticos. ${ }^{2}$

Em linhas gerais, Thomasius propunha a secularização do Estado confessional de alguns territórios alemães, dentre os quais a Saxônia, sua terra natal. Isso implicava, decerto, retirar dos teólogos - sobretudo dos luteranos - o poder sobre matérias de governo e de administração pública; ademais, envolvia extirpar sua influência no ambiente acadêmico. Nesta passagem, Thomasius põe a claro seu projeto:

Em poucas palavras, em cada estado há apenas uma majestade ou poder governante superior, por meio de cujo poder supremo um magistrado cristão faz a mediação entre as leis de toda a conduta e seus súditos (...). A lgreja está no estado, e o estado não está na Igreja. No Novo Testamento, Cristo e os apóstolos não dão à Igreja nenhuma capacidade de governar. Em um estado não pode haver duas autoridades soberanas com o poder de fazer leis. O clérigo e os outros membros das Igrejas estão sujeitos à autoridade secular. Portanto, a autoridade secular pode regular as atividades dos sacerdotes, mesmo aquelas que dizem respeito à religião, na medida em que tais leis não comandam nada que seja contrário à lei divina geral (Thomasius, 1701, p. 38).

Vejamos, agora, como o projeto thomasiano de secularização e guinada à prática ganhou corpo institucional na Universidade de Halle.

\section{Halle e a mudança thomasiana no currículo universitário - as Kameralwissenschaften}

A Universidade de Halle foi um exemplo paradigmático de uma universidade da Aufklärung. Com a "crise" vivida na consciência europeia nos séculos 17 e 18, ${ }^{3}$ ocorre também uma radical mudança na hierarquia das ciências, cujo reflexo pode ser

\footnotetext{
2 Segundo Hunter, os principais representantes da filosofia jurídica civil, do pietismo e do racionalismo metafísico em Halle seriam, respectivamente, Thomasius, Francke e Wolff (Hunter, 2004, p. 579).

30 termo é do clássico estudo de Paul Hazard (1995).
} 
visto, em sua face institucional, nas universidades e na ordenação das disciplinas do currículo universitário. De um modo mais amplo, a filosofia sai da tutela da teologia e adquire uma certa "dignidade" como disciplina ou ciência autônoma. Como afirma Jonathan Israel,

foi apenas com a crise intelectual do final do século 17 que a antiga hierarquia de estudos - com a teologia como a disciplina suprema e a filosofia e as ciências como meras subservientes - desintegrou-se. Com isso, a filosofia libertou-se de sua subordinação anterior e tornou-se novamente uma força independente potencialmente contrária à teologia e às Igrejas (Israel, 2001, p. 10).

No cenário alemão, que aqui nos interessa, essa reordenação das disciplinas ganhou uma especificidade notável: não só a filosofia, mas também - e sobretudo - a jurisprudência recebe dignidade própria e independência em relação à teologia. À época, o currículo das universidades alemãs e europeias era dividido segundo uma estrita hierarquia de faculdades "inferiores" e "superiores". A faculdade "inferior" era a filosofia, que ficava a cargo do "Grundstudium", algo como um "ciclo básico"; as faculdades "superiores", que qualificavam seus alunos para algum ofício, eram elas mesmas divididas hierarquicamente: a teologia recebia a precedência, seguida pela jurisprudência e pela medicina. Tal sequência hierárquica das faculdades era considerada algo dado e representava como que um tratamento "natural" das ciências. Os teólogos e os clérigos controlavam todas as disciplinas a serem ensinadas em cada faculdade. Na jurisprudência, por exemplo, o direito natural cristão moldava o quadro teórico de todas as subdisciplinas jurídicas (cf. Schneider, 1967, p. 119-331). A Aufklärung e, mais especificamente, a Universidade de Halle começaram a mudar esse quadro:

[E]ssa ordenação da universidade em faculdades inferiores e superiores foi questionada ao longo da Aufklärung de três maneiras. Primeiro, os juristas concorriam com os teólogos pela posição de destaque - em Halle, a teologia era explicitamente a faculdade superior, contudo, os altos vencimentos dos jurisconsultos mostravam que os juristas haviam superado os teólogos na avaliação do príncipe territorial. Segundo, a faculdade filosófica se despedia de sua função meramente propedêutica, preparatória e serviçal, reivindicando o estatuto de uma ciência fundamental - essa revalorização ocorreu nas gerações seguintes em Halle, sobretudo através de Christian Wolff. Terceiro, a medicina aproveitou-se da ascensão da pesquisa sobre a natureza e, por seu turno, fez fraquejar a hierarquia de disciplinas tradicional - a Universidade de Halle avançou ao centro daquela antropologia do "homem completo" que dominou a fase áurea e tardia da Aufklärung (Martus, 2015, p. 99-100).

A Universidade de Halle dava uma feição institucional a um movimento, próprio da Aufklärung, de secularização da sociedade e de guinada à prática, ou seja, de valorização de disciplinas e saberes voltados à manutenção da coesão política e religiosa e à condução da máquina pública. Nesse contexto, não apenas a tradicional hierarquização das ciências era posta em xeque, como também novas disciplinas 
eram introduzidas no currículo universitário, sempre sob os auspícios do príncipe ou Fürst. ${ }^{4} \mathrm{~A}$ institucionalização de certas disciplinas, seja no sistema universitário, seja na máquina pública, tinha como função, além de garantir a eficiência da administração do Estado, legitimar o governo estatal então incipiente nos territórios alemães (Rüdiger, 2005, p. 163-164). O repetido fracasso em promover reformas e o constante perigo do retorno das guerras confessionais - lembremos da paz de Augsburg, em 1555, que estabeleceu a tolerância do luteranismo no Sacro Império Romano-Germânico, e a já mencionada paz de Westfália, em 1648, que estabeleceu a tolerância da prática das várias confissões cristãs nos territórios alemães - fizeram com que se fortalecesse o estudo institucional do Estado e da política (cf. Hellmuth, 2004).

Ao contrário de outros países europeus, como França e Inglaterra, nos territórios alemães a Aufklärung teve como lócus privilegiado as universidades. Os Aufklärer alemães eram majoritariamente professores e também gelehrte Räte, ou seja, consultores ou conselheiros nas cortes dos Fürsten, nos estamentos nobres e em conselhos de territórios estatais do Sacro Império Romano-Germânico (cf. Hammerstein, 1986). As universidades haviam sido instituições estratégicas para os Fürsten de territórios recém-formados e nos movimentos religiosos reformadores durante o período central da Reforma, fornecendo-lhes os quadros (teólogos, juristas, clérigos) necessários para a montagem administrativa e judicial do Estado confessional. Donde se explicam o fato e a própria necessidade de que Thomasius combatesse a infiltração teológica e propusesse a reforma universitária de dentro da própria instituição. Vale a pena reproduzir o diagnóstico de Hellmuth:

As universidades do século 18 desempenharam um papel crucial aqui, especialmente aquelas que eram bastiões da Aufklärung, como Halle e Göttingen. Nestas universidades inúmeras disciplinas, conhecidas em seu conjunto como "ciência do governo", foram estabelecidas (...). Elas incluíam o direito natural, economia, as disciplinas especificamente alemãs Kameralwissenschaft e Polizeiwissenschaft. Ademais, havia a Universitätsstatistik (estatística universitária), que, apesar de seu nome, não tinha nada a ver com aritmética política. Gottfried Achenwall, professor de Göttingen, a definia como a "teoria da constituição política dos Estados individuais descrita nos termos de suas partes específicas" (...). As "partes" que eram consideradas como merecedoras de descrição incluíam território e população, constituição e administração, exército e finanças. Desse modo, exigia-se um conhecimento íntimo das condições internas nos estados contemporâneos. O direito natural, assim, tinha uma outra função bem

\footnotetext{
4 "Novos conceitos e textos tiveram de ser introduzidos paulatinamente em cada faculdade. Usualmente, o que abria as portas era o comando do príncipe em vez do consentimento do professor. Professores esclarecidos apenas podiam ganhar cadeiras e outras posições universitárias por meio da proteção e patronato do príncipe. Os príncipes, contudo, geralmente não estavam interessados em debates teóricos. Sua predileção era muito mais pelos assuntos práticos, como pela introdução, no currículo universitário, de novas disciplinas, como, por exemplo, a 'Cameralística', que podia provar-se útil para encher os cofres do estado e promover a prosperidade geral. Além disso, eles usavam filósofos para combater a influência de teólogos e clérigos, para modernizar seu sistema político e incrementar a atratividade das universidades territoriais para estudantes estrangeiros e de muitos recursos" (Weber, 2003. p. 414).
} 
diversa. Como o principal elemento do complexo de disciplinas estudadas na ciência do governo, ele pretendia transmitir conhecimentos fundamentais sobre política, sociedade e direito. Isso incluía a definição dos objetivos e fins do Estado, conforme eles surgem a partir da natureza humana. As outras disciplinas incluídas na ciência do governo, Kameralwissenschaft e Polizeiwissenschaft (...) eram então exigidas para descrever os meios e os caminhos pelos quais aqueles objetivos e fins podiam ser atingidos. Os contornos de tais disciplinas eram, não raro, pouco nítidos, mas elas se unificavam sob um único leitmotiv, a saber, que o objetivo da ciência era ser útil ao Estado (Hellmuth, 2004, p. 452).

Thomasius foi o grande artífice dessa renovação da universidade da Aufklärung. A sua reordenação das ciências e disciplinas é guiada pelo remanejo, como cerne da nova universidade prussiana, da jurisprudência e do direito natural secularizado, em torno dos quais se aglutinam as disciplinas "práticas” para a boa condução e administração do governo. Com efeito, ao invés de se ver como um "philosophe" ${ }^{5}$ que buscaria agir a partir apenas da sua influência em debates públicos sobre educação, moral, artes, economia, política, etc., Thomasius se via como um reformador "de dentro", que usava sua influência institucional e administrativa para atingir o objetivo de reforma da sociedade prussiana segundo ideais iluministas. A introdução das novas disciplinas no currículo universitário tinha como objetivo principal formar uma casta de funcionário públicos (os Beamte) "secularizados", “ilustrados” e voltados à boa administração do Estado. Antes de analisar mais detidamente a Polizey, cumpre empreender uma tentativa de definir o que seria essa Kameralwissenschaft que serve como uma espécie de denominador comum das novas disciplinas práticas. ${ }^{6}$

A cameralística (Kameralwissenschaft, Cameral-Wesen, Kameralistik) designava, no singular, uma aplicação pública de saberes e procedimentos privados, relativos aos súditos e funcionários estatais; no plural, as Kameralwissenschaften designavam o conjunto de disciplinas que eram úteis para a instrução e formação de administradores públicos. Num primeiro momento, no início do século 18 , estas disciplinas incluíam, além da Polizey, sobretudo a Ökonomie. "O tema da Ökonomie abrangia assuntos que poderiam se aplicar tanto ao Fürst como ao proprietário de terras privado (por exemplo, a tributação, arrendamento e venda de terras, além dos rudimentos da agricultura)" (Lindenfeld, 1997, p. 17). Segundo Johann Peter Ludewig, um importante cameralista da época,

um Fürst que aumenta a receita de seu território [Land] por meio de comércio e negócios, e que arrecada mais do que gasta, é denominado um bom Wirt (...). [D]aqui se segue que, assim como a arte de ganhar a vida pertence ao conjunto dos homens comuns, aos homens da cidade e aos campesinos, ela também pertence ao Fürst e ao conjunto do território; assim, a palavra Wirtschaft pode ser considerada e utilizada para todos eles (Ludewig, 1727, p. 146).

\footnotetext{
5 Segundo Israel, o termo "philosophe" para designar os então novos "livres pensadores" franceses é de responsabilidade de Thomasius (Israel, 2001, p. 8).

6 Seguimos, na sequência, sobretudo Lindenfeld, 1997.
} 
O termo germânico Wirtschaft para designar a Ökonomie mostra, pois, que a atividade econômica mais fundamental deveria ser não apenas a troca ou a produção, mas também a boa administração e alocação de recursos.

A outra disciplina das Kameralwissenschaften é a Policeywissenschaft, a "ciência da política” ou apenas "política” (Policey, Polizey ou Polizei), entendida não mais sob a chave escolástico-aristotélica de uma disciplina das virtudes civis e políticas do Fürst (cf. Scattola, 2003), mas, antes, como a ciência do bom governo a ser empregada pelos Fürsten na crescente centralização de poder em seus territórios - algo, pois, próximo ao sentido de “polícia” como controle social e monopólio do uso da força:

A palavra alemã [Policey] surgiu no século 15 , primeiramente no contexto de um governo civil bem conduzido, mas logo foi transferida para o contexto territorial. Em 1530, o Sacro Imperador Romano emitiu um decreto de Polizey para todo o Império. 0 impetus por detrás desse uso - que se manifestava em um crescente afluxo de decretos - era a asserção da vontade do regente sobre os estamentos em nome do bem comum. Muito frequentemente, os decretos tinham a ver com a restrição de luxos, regulação de adornos, imposição de práticas religiosas e, de modo geral, extinguir a imoralidade em todas as áreas, de relações matrimoniais ao empréstimo de dinheiro. Na Alemanha protestante, a Polizey preencheu um vácuo criado pela ausência de regulação, por parte da Igreja, de escolas, matrimônio e outros sacramentos (Lindenfeld, 1997, p. $18)$.

É certo que essa consolidação do novo conceito de política não se deu de forma repentina. Na transição entre a tradição escolástico-aristotélica para o conceito "moderno" de política coexistiram, lado a lado, dois sentidos de política, a saber, política concebida no interior do direito natural, e a política como prudentia. A primeira lidava com a natureza dos Estados, tipos de governo, constituições, etc. Um tal nível de generalidade, contudo, criou espaço para um segundo nível, a saber, o da prudentia como "sabedoria" de governo, dos Estados particulares, suas leis e sua administração. O nível geral, do direito natural, constituía as normas e limites; o segundo, o da prudentia, desenvolvia os meios para sua implementação. Na próxima seção, veremos com mais detalhes a articulação entre esses dois níveis do “novo” conceito de política.

Concebida no quadro das Kameralwissenschaften, a política, portanto, representava a aplicação da disciplina social absolutista no contexto de um direito natural secularizado que fornecia os fins para os quais tal disciplina era dirigida. Para Thomasius e Wolff, "esses fins foram progressivamente articulados em termos de felicidade, e a correspondente ênfase da Polizeiwissenschaft recaía no bemestar e na prosperidade do Estado e de seus súditos" (Lindenfeld, 1997, p. 20). Ao passo que na Ökonomie o foco era no povo ou na comunidade, na Polizei o foco era no Estado. Em todo caso, assim como nas demais disciplinas da Kameral-Wesen, o objetivo da Polizei era a boa administração, ou seja, o objetivo era adaptar meios a fins, seja no balanço das contas públicas ou no esforço de obtenção de lucro com 
terras, seja na promoção da felicidade da comunidade política. Assim, “economia e administração pública não eram opostas, mas, pelo contrário, dois lados da mesma moeda tecnocrática" (Lindenfeld, 1997, p. 20).

Com efeito, a cameralística, entendida como o conjunto de disciplinas práticas direcionadas para a boa administração pública, tinha como principal função promover o interesse público, não apenas por cuidar das finanças e dos recursos do Estado, mas também por servir como uma espécie de orientação prática a todos os súditos em suas atividades produtivas ligadas ao Estado:

[A] cameralística não consiste apenas em arrecadações e dispêndios, e no correto cálculo destes, mas, antes, ela diz respeito também a que se promova o interesse de todo o território [Land], e que se provejam instrumentos ao homem comum, isto é, que se the diga de onde ele deve retirar [algo] quando the é ordenado que ele deve dar algo (Bechers, 1668, Dedicatio, sem número).

Com o desenvolvimento da noção de prosperidade e promoção do bem comum nos territórios do Sacro Império Romano-Germânico, mais notadamente na Prússia, a cameralística se tornava uma disciplina popular no ambiente universitário alemão do século 18 , impulsionada pela nova reorientação política e prática dos saberes acadêmicos. Gasser, o primeiro professor de Kameralistik na Universidade de Halle e, de forma geral, na Alemanha, escreve no prefácio de seu livro Einleitung zu den ökonomischen, politischen und Cameral-Wissenschaften que Thomasius foi o primeiro a apontar para a deficiência das universidades em não possuir cadeiras de Kameralwissenschaften. No capítulo 17, § 1 de Cautelen der Rechts-Gelahrtheit, Thomasius escreve: "Com todo o direito, a Ökonomie deveria ser ensinada nas universidades, e ser apontado um professor para tanto". As causas para tal lacuna, segundo Thomasius, originariam de um menosprezo pelas ciências práticas, pelas disciplinas que ensinam "o que sabem o homem comum e o servo", ou ainda, por aquelas disciplinas que não se enquadravam no aristotelismo de então. Segundo Gasser, a ciência cameral e da política (Cameral-und Policey-Wesen) tinha por função "capacitar e tornar apto um homem jovem a servir seu senhor e o território de modo honesto" (Gasser, 1729, p. 4).

Trata-se, decerto, de uma nova forma de condução dos negócios públicos e, no limite, de conceber a política. Contudo, em lugar de uma forma política ligada ao laissez faire dos indivíduos privados, nos territórios alemães a impregnação absolutista, de condução centralizada das atividades dos súditos, ainda era inquestionável. Beckmann, professor de cameralística em Göttigen, escreve:

A cameralística tem por objetivo as arrecadações do regente ou do caixa público, de onde os gastos do Estado são custeados, e, como deve ser proporcional às posses do povo, este último nunca poderá atingir uma política racional. 0 cidadão procura sempre seu interesse próprio! Por isso ele vive no Estado e contribui com o que é seu para os gastos [do Estado], de modo a poder aprender um ofício (...) e impulsionar 
o primeiro [o Estado], sem que este se detenha no cuidado pelo último [o cidadão]. Este apenas obedece quando o governo comanda que ele compreenda e observe seus próprios deveres. Assim, o Estado é a máquina artificial montada pelos homens, na qual um conjunto de rodas e engrenagens pequenas e grandes encaixam umas nas outras (Beckmann, 1777, Vorrede, sem número).

Thomasius critica a radical separação entre economia e política contida na doutrina aristotélica e neoaristotélica da filosofia prática (cf. Thomasius, 2006, p. 421-437). Tanto a forma como o conteúdo da filosofia aristotélica e sua impregnação no ambiente alemão impediam a recepção acadêmica da cameralística como parte integrante do ensino universitário. Diante desse diagnóstico é que Thomasius encorajou, em Halle, as primeiras iniciativas pela inclusão da economia cameralística como disciplina acadêmica (Rüdiger, 2005, p. 158). A inaptidão dos professores aristotélicos de ética e política é criticada também pelos alunos de Thomasius. Christoph Henrich Amthor, discípulo de Thomasius em Halle que escrevia sob o pseudônimo de Anastasio Sincero, pergunta em seu Project der Oeconomic in Form einer Wissenschaft por que razão as "ciências econômicas (...), diferentemente de outras disciplinas, não são ensinadas em escolas e universidades", embora elas "sejam capazes de levar nutrição, riqueza e poder a cidades e territórios inteiros" (Apud Rüdiger, 2005, p. 158). Ele defendia a instituição de um órgão de administração econômica pública [ökonomischen Kameral- und Polizeiverwaltung] liderado por “diretores econômicos" que

dependeriam imediatamente da soberania territorial e de suas instruções, e sob tal forma teriam um poder perfeito para promover, da melhor maneira possível, o bemestar e a soberania do território (Apud Rüdiger, 2005, p. 158).

Para ele, a economia seria dividida em Oeconomicam naturalen, que lidaria com os ramos produtivos (agricultura, comércio), e a Oeconomicam politicam, que lidaria com a melhor forma de gastar os recursos públicos e seria diretamente conduzido pelo Fürst. A segunda disciplina é, decerto, a mais importante. Rüdiger argumenta ocorrer aqui uma "economização da política" como “princípio de soberania” (Rüdiger, 2005, p. 159). Isso provocou conflitos políticos entre os territórios alemães: "Na luta pela implementação de uma legislação soberana dos territórios e pelo monopólio do direito de tributação, os meios jurídico-morais tradicionais da soberania estamental chegaram a seus limites" (idem, p. 160). A institucionalização da economia e sua transformação num dispositivo de governo pode ser considerada, assim como ocorria na política, como um instrumento de (auto)disciplina da casta de funcionários públicos. Um exemplo claro do problema político da institucionalização da economia na administração pública na Prússia e demais territórios alemães como (auto)disciplina é o estabelecimento de um sistema tributário eficiente e regulado burocraticamente que lhes garantisse hegemonização financeira e cultural - de 
acordo, portanto, com o intuito da Aufklärung de um projeto de guinada à prática e à boa administração estatal.

\section{A institucionalização da política como doutrina da prudência}

Um momento decisivo para o desenvolvimento da política como Policey foi a sua institucionalização acadêmica por meio da governamentalização das universidades (Rüdiger, 2005, p. 144). Essa inserção acadêmica da política implicou conceitualizála para além dos limites temáticos impostos pela política clássica de proveniência aristotélica, o que, por sua vez, envolveu uma modificação metodológica e de orientação normativa. Nesse contexto, a Universidade de Halle e a teoria política de Thomasius foram de suma importância.

Como já mencionado, a política passa a ser entendida no sentido de Policey, ou seja, como boa administração pública, no mesmo campo conceitual da ideia de Kameralistik, isto é, como boa gestão dos recursos públicos, não mais no sentido ético de uma doutrina sobre a virtude dos regentes.

Thomasius considerava a universidade (...) como um "Seminaria Ecclesiae \& Reipublicae" (cf. Thomasius, 1994, p. 197), isto é, como um centro de treinamento para a administração eclesiástica e estatal. Com isso, ele coloca a ciência universitária a serviço de um discurso autônomo da política referido aos príncipes territoriais (Rüdiger, 2005, p. 145).

A "verdadeira política” implicava, para ele, a elucidação e "Aufklärung” dos "segredos do papado" (Thomasius, 1717, p. 345) (o qual, segundo Thomasius, buscava apenas o poder), além da recusa da escola aristotélica de seu tempo. Ele denuncia, assim, a forma especificamente católica do aristotelismo, qualificada por ele como uma mera técnica de poder. Para romper por completo com essa tradição, Thomasius via como necessária a reformulação institucional do discurso teórico sobre a política.

A relação da doutrina política universitária com o conjunto de saberes mundanos era considerada por Thomasius como precária justamente por ela ter sido sempre parte de um sistema científico que ainda não havia rompido, de forma consequente, com sua origem escolástico-católica (Rüdiger, 2005, p. 146).

A teoria política, assim como as demais ciências escolásticas, teria como grande falha considerar seu objeto à luz da perspectiva eclesiástica, à luz dos interesses dos teólogos, e não segundo o fim do poder secular da comunidade política. Essa ciência política aristotélica colonizada pela teologia se reduziria, nas palavras de Thomasius, a

arcana politica, em virtude dos quais o papa, como seus clérigos, de maneira completamente imperceptível, joga o governo mundano pra debaixo do tapete e faz de um superior regente um mandatário mundano dependente dos comandos dos clérigos (Thomasius, 1717, p. 27). 
0 alvo imediato de Thomasius é o aristotelismo, modernizado por Melanchton, de matriz luterana. Para ele, embora se oriente ao Fürst como ponto de referência político supremo, o método escolástico contemplativo empregado bloqueia o valor prático das ciências para a comunidade política secular. A falta de referências mundanas por parte da ciência reproduz, no mundo acadêmico protestante, a hegemonia simbólica do clericalismo e do poder católico mundial:

Segundo sua própria formação, os monges são devotados à vida contemplativa e não se entregam à vida prática, à qual indiscutivelmente pertence a governança [Haushalt] (...). As profissões que foram assim formadas no papado consistem igualmente nas Speculationibus e são, em sua grande maioria, inúteis. As profissões da filosofia nas universidades protestantes tampouco estão hoje em dia completamente libertadas dessa falha (Thomasius, 1717, p. 274).

Para Thomasius, essa hegemonia da religião nos afazeres mundanos mostraria sua face institucional mais clara na precedência normativa da faculdade teológica na hierarquia das disciplinas universitárias. A faculdade teológica propunha a precedência da vita contemplativa, que, assim, servia apenas à conservação do poder político eclesiástico. A secularização dos estatutos políticos pelo Fürst promovia, por sua vez, "uma vida ativa, sem a qual a filosofia política não poderia pensar, nem se quisesse, o problema do governo (prudentia regnativa) como uma doutrina da prudência" (Thomasius, 1699, p. 54).

Nesse contexto, a já mencionada "doutrina da prudência", revitalizada por Thomasius, ganha novo destaque. Thomasius define a "prudência" como um dos ramos da política. ${ }^{7}$ Ela seria "uma doutrina que mostra sobretudo como se deve cuidar contra equívocos e impedimentos do bom" (Thomasius, 1699, p. 8-9). Para compreender o que é o bom, é necessário o auxílio das outras disciplinas pertencentes à Sittenlehre, ou seja, à doutrina moral ou dos costumes; a prudência meramente ensina sobre os meios para se atingir determinado fim, o qual, por sua vez, seria estipulado alhures. A prudência se dividiria em prudentia consultatoria e prudentia legislatoria ou civilis:

A prudência consultatória [rathgebende Klugkeit] é ou geral ou civil. A primeira ensina todos os homens, independente do estamento ou sociedade à qual pertencem, como eles devem bem executar suas ações e propósitos (...). A prudência civil, contudo, visa sobretudo ao governo de uma república [Republic] e todas as partes da majestade [Majestät], portanto, costuma-se também denominá-la a prudência que dá leis, pois a preocupação fundamental de um regente deve ser a de dar leis a seus súditos e estabelecer as regras de justiça (Thomasius, 1699, p. 39).

Segundo o diagnóstico de Thomasius, o aristotelismo político dos escolásticos

7 Rüdiger argumenta que Thomasius segue Maquiavel numa concepção neutra de política, independente de moral e religião. Hammerstein, contudo, acentua o aspecto moral da política para Thomasius, compreendida como Sittenlehre. 
perdia de vista o aspecto pragmático da prudência: não apenas dar conselhos, mas indicar os meios para atingir os fins propostos (Thomasius, 1699, p. 66). Também aqui se revela a visada contemplativa, e não prática, da apropriação escolástica. Ora, na política trata-se não de regras abstratas, mas, antes, de uma arte de governo, sobre "como posso reger pessoas mal instruídas" (idem, ibidem). Por meio da prudentia civilis a (auto)disciplinarização dos regentes torna-se uma condição crucial para a pacificação da comunidade política e para a disciplinarização dos regidos. Em suma, Thomasius propõe em sua doutrina da prudência civil "a autodisciplinarização das elites administrativas, isto é, o governo moral de si mesmo, como pressuposto para a governamentalização dos súditos” (Rüdiger, 2005, p. 148).

Adoutrina thomasiana da prudência como parte central da política se desenrolou ao longo do seu pensamento, atingindo seu momento mais maduro com a doutrina do decoro, exposta sobretudo nos Fundamenta iuris naturae et gentium. 0 decoro (decorum ou Wohlanständigkeit) é, de modo geral, "uma qualidade moral do fazer e deixar de fazer humanos segundo a qual um homem procura fazer companheiros [Freunde] de modo racional" (Thomasius, 2006, p. 368). Mais especificamente, o "decoro político" é "a doutrina sobre como se deve fazer companheiros" (Thomasius, 2006, p. 369). O decoro exige que se abstenha de certas ações que provocam "asco" em muitos outros homens (idem, p. 386). Trata-se, pois, de uma espécie de domínio sobre os próprios afetos, uma disciplina moralis sobre certas práticas sociais. Ora, ao passo que "a ética ensina os princípios do que é honesto, a política ensina os princípios do que é decoroso" (Thomasius, 2003, p. 104). Assim, “já com sua teoria do decoro político, Thomasius faz a passagem de um governo religioso da alma para o governo político do homem no interior de uma doutrina da política e da prudência" (Rüdiger, 2005, p. 150). A doutrina da prudência é dirigida primariamente aos funcionários do Estado e não ao soberano em si. Ou seja, a prudência política esboçada por Thomasius não visa a vita activa da soberania, mas, antes, dos membros do próprio poder executivo, a "vida ativa de seus teólogos, jurisconsultos e médicos (...), o prelado, os conselheiros, juízos, advogados, a cura dos pacientes” (Thomasius, 1717, p. 274). Como escreve Rüdiger,

a administração da soberania dos príncipes, para além de sua fundamentação jurídica no ius publicum, permanecia, para Thomasius, fora da doutrina política universitária. A prudência monárquica de governo como ponto de referência normativo que estabelece os fins da prudência política não se sujeita a nenhuma regulação racional e permanece, assim, o refúgio de uma autoridade transcendente. Como doutrina dos meios, a prudência política é indiferente a seus fins e contém, portanto, um caráter técnico-instrumental (Rüdiger, 2005, 151).

A ampliação da influência do conceito de prudência e do político para toda a casta administrativa do corpo político - entendido no sentido acima descrito do 
poder executivo, ou seja, como doutrina dos meios, não dos fins do poder - implica transpor o ensino da prudentia civilis da faculdade de filosofia para a faculdade jurídica. Como nos territórios alemães eram sobretudo os juristas que tratavam dos assuntos públicos, Thomasius acreditava fazer mais sentido que a jurisprudência, que lidava com as "leis naturais e civis", cuidasse, ademais, dos "assuntos políticos e civis" (Thomasius, 1699, p. 68). Isso, decerto, implicava uma mudança institucional. Para Thomasius, era mais apropriado

que os juristas, nas universidades, ensinassem aos seus ouvintes tanto a prudência geral como a prudência para reger, de modo que eles não devessem aprender pelo exercício aquilo que lhes era necessário em seus cargos futuros (idem, p. 68-69).

Contudo, Thomasius não acreditava que a política se deixava deduzir a partir de princípios jurídicos abstratos ensinados em sala de aula. Pelo contrário, ela se construía também a partir de sua prática efetiva. A partir de 1714, Thomasius ficou a cargo da comissão, nomeada por Friedrich Wilhelm I, que deveria conceber o Allgemeines Landrecht für die Preußischen Staaten, o qual serviria como modelo para a unificação e reconfiguração administrativa e jurídica dos territórios pertencentes a PrússiaBrandemburgo (Rüdiger, 2005, p. 155). A experiência - malsucedida - fortaleceu em Thomasius a crença de que a política não pode ser desenvolvida a partir de princípios jurídicos descolados das especificidades político-sociais dos territórios nos quais devem ser aplicados. De acordo, portanto, com a guinada à prática que marcou a especificidade da Aufklärung.

\section{Referências}

Bechers, J. J. (1668). Politischer Discurs Von den eigentlichen Ursachen deß Auf- und Ablebens der Städt, Länder und Republicken.

Beckmann, J. (1777). Anleitung zur Technologie, oder zur Kentniß der Handwerke, Fabriken und Manufacturen, vornehmlich derer, die mit der Landwirthschaft, Polizey und Cameralwissenschaft in nächster Verbindung stehn : Nebst Beyträgen zur Kunstgeschichte.

Gasser, S. P. (1729). Einleitung zu den ökonomischen, politischen und CameralWissenschaften. Halle.

Göhler, G. (2011). Politische Theorien des 17. Und 18. Jahrhunderts in Deutschland: ein Überblick. In: Göhler, G. \& Heidenreich, B. (eds.) Politische Theorien des 17. Und 18. Jahrhunders. Staat und Politik in Deutschland. Darmstadt/Mainz: Verlag Philipp von Zabern.

Hammerstein, N. (1972). Jus und Historie: ein Beitrag zur Geschichte des historischen Denkens an deutschen Universitäten im späten 17. und im 18. Jahrhundert. Göttingen : Vandenhoeck \& Ruprecht.

Hammerstein, N. (1986). Universitäten-Territorialstaaten-Gelehrte Räte. In: Schnur, $\mathrm{R}$ (ed.). Die Rolle der Juristen bei der Entstehung des modernen Staates. Berlin: Duncker \& Humbolt. 
Hazard, P. (1995). La crise de la conscience européenne: 1680-1715. Paris: Fayard.

Hellmuth, E. (2004). Enlightenment and Government. In: Fitzpatrick, M.; Jones, P.; Knellwolf, C. \& McCalman, I. (eds.). The Enlightenment World. New York: Routledge.

Hunter, I. (2004). Multiple Enlightenments: Rival Aufklärer at the University of Halle, 1690-1730. In: Fitzpatrick, M. et alli. (eds.). The Enlightenment World. London: Routledge.

Hunter, I. (2007). The Secularisation of the Confessional State. Cambridge: Cambridge University Press.

Israel, J. (2001). Radical Enlightenment: Philosophy and the Making of Modernity, 1650-1750. Oxford: Oxford University Press.

Lindenfeld, D. (1997). The Practical Imagination, The German Sciences of State in the Nineteenth Century. Chicago: University of Chicago Press.

Ludewig, J. P. (1727). Die, von Sr. Königlichen Majestät, unserm allergnädigsten Könige, auf dero Universität Halle, am 14. Julii 1727 neu angerichtete Profesion in Oeconomie, Policey, und Cammer-Sachen. Halle.

Martus, S. (2015). Aufklärung. Das deutsche 18. Jahrhundert - Ein Epochenbild. Berlin: Rowohlt.

Rüdiger, A. (2005). Staatslehre und Staatsbildung. Die Staatswissenschaft an der Universität Halle im 18. Jahrhundert. Tübingen: Max Niemeyer.

Scattola, M. (2003). Dalla virtù alla scienza. La fondazione e la transformazione della disciplina politica nell'età moderna. Milano: Franco Angeli.

Schneider, H-P. (1967). Justitia universalis: Quellenstudien zur Geschichte des „Christlichen Naturrechts“ bei Gottfried Willhelm Leibniz. Frankfurt am Mainz: Vittorio Klostermann.

Thomasius, C. (1699). Summarischer Entwurf der Grundlehren, die einem Studioso Juris zu wissen und auf Universitäten zu lernen nötig sind. Halle.

Thomasius, C. (1701). Dreyfache Rettung des Rechts Evangelischer Fürsten in Kirchen-Sachen. Frankfurt am Main.

Thomasius, C. (1717). D. Melchiors von Osse Testament gegen Hertzog Augusto Churfürsten zu Sachsen (1556). Anitzo zum ersten mahl völlig gedruckt. Auch hin und wieder durch nützliche Anmerckungen erläutert. Nebst einer Vorrede und Anhang. Zum Gebrauch des Thomasischen Auditorii. Halle.

Thomasius, C. (1994). Kleine Teutsche Schriften. Halle, 1701; repr. Hildesheim: Georg Olms.

Thomasius, C. (2001). Drey Bücher der Göttlichen Rechtsgelehrtheit (...). Halle, 1709. repr. Band 4 der Ausgewählten Werke von Christian Thomasius. Hildesheim [u.a]: Georg Olms Verlag.

Thomasius, C. (2003). Grundlehren des Natur- und Völkerrechts. Halle, 1709. repr. Band 18 der Ausgewählten Werke von Christian Thomasius. Hildesheim: Georg Olms Verlag.

Thomasius, C. (2006). Cautelen zur Erlernung der Rechtsgelehrtheit. Halle, 1713. repr. Hildesheim: Georg Olms. 
Trevisan, D. K (2020). Christian Thomasius e a Aufklärung. Kriterion, 61 (145), 151 172. DOI: https://doi.org/10.1590/0100-512x2020n14508dkt

Weber, W. (2003). The German Universities and Intellectual Freedom in the Early Modern Period". In: Fédération Internationale des Universités Catholiques: Université, Eglise, Culture. L'université catholique à l'epoque moderne de la réforme à la révolution seizième à hiutième siècles, Paris: Pierre Hurtubise.

Recebido em: 09.06.2020

Aceito em: 09.11.2020

Esta obra está licenciada com uma Licença Creative Commons Atribuição-NãoComercial- 